\title{
Apprehensive parents: a qualitative study of parents seeking immediate primary care for their children
}

\author{
Marjolijn Hugenholtz, Christian Bröer and Rineke van Daalen
}

\author{
ABSTRACT \\ Background \\ Children are more frequent users of out-of-hours \\ primary care than other age groups, although their \\ medical problems are less urgent. \\ Aim \\ To gain insight into the health-seeking behaviour of \\ parents who ask for immediate medical attention for \\ their children \\ Design of study \\ Qualitative analysis of interviews and telephone calls. \\ Setting \\ A general practice out-of-hours cooperative that caters \\ for approximately 300000 people in The Netherlands.

\section{Method} \\ A semi-structured interview was conducted with 27 \\ parents who had consulted their own GP or an out-of- \\ hours facility for primary care because they wanted \\ urgent medical attention for their child who was sick. \\ Forty-four telephone calls from parents seeking \\ medical care for a child were analysed.

\section{Results} \\ Recognising symptoms in a child started with the \\ observation of a deviation from the child's normal \\ appearance or behaviour. Parents decided to contact \\ medical services when they felt they lost control of the \\ situation. Most parents consulted because they wanted \\ to rule out or prevent serious disease, not because of the \\ condition itself; not wanting to take a risk with their child \\ was an important motivation. In an attempt to rule out \\ serious disease at home, parents also attempted \\ diagnostic procedures they had copied from \\ professionals.

\section{Conclusion} \\ Worry of parents and their health-seeking behaviour \\ can be seen as an expression of the central role of risk \\ regulation in modern society. Doctors need to realise \\ their own contribution to the way parents want to rule \\ out serious disease in their children. Improving parents \\ knowledge will not solve the problem of inappropriate \\ use of out-of-hours facilities.

\section{Keywords} \\ after-hours care; child; family practice; health \\ behaviour; parents; risk.
}

\section{INTRODUCTION}

Data from general practice cooperatives in the UK and the Netherlands show that children make more use of out-of-hours care than members of other age groups, although the health problems of these children are less urgent from a medical point of view. ${ }^{1,2}$

Literature shows that parents consult a GP on the same day when they are worried and when they discover new, unknown, or disturbing symptoms in their children..$^{3-5}$ Parents worry when they think that symptoms are threatening to their children, and especially when they feel they have lost control of the situation. ${ }^{4,5}$ Fever appears to be the main symptom that causes concern, followed by coughing and poor sleeping, eating, or drinking. ${ }^{4,6,7}$ Previous experience with doctors and illness in children influences parents' decisions to seek medical help after hours. ${ }^{8}$

It is known that parents' perceptions are crucial, but it is not known why some symptoms are considered alarming. Knowledge about underlying health beliefs is relevant if we want to close the gap between parents who ask for immediate medical attention for their children at all times, and doctors who feel that some parents are making inappropriate use of out-of-hours facilities. ${ }^{9,10}$ This study asked the following questions:

- How do parents decide that their sick child has symptoms that require immediate medical attention?

M Hugenholtz, MBBS, MSc, GP; C Bröer, PhD, assistant professor; $\boldsymbol{R}$ van Daalen, $P h D$, assistant professor, Department of Sociology and Anthropology, University of Amsterdam, Amsterdam, The Netherlands.

Address for correspondence

Marjolijn Hugenholtz, Gezondheidscentrum Bovenmaat, Wadden 34, 1274GK Huizen, The Netherlands.

E-mail: m.hugenholtz@wgchuizen.nl

Submitted: 24 March 2008; Editor's response: 4 June 2008; final acceptance: 18 August 2008.

(-)British Journal of General Practice.

This article was originally online first. Cite this article as: Br J Gen Pract 2009; 59: 173-179. Advance online publication. DOI: 10.3399/bjgp09X394996 


\section{How this fits in}

Children attend more out-of-hours primary care than adults for medical problems that are less urgent, and worry has been known to be an important contributor to parents' help-seeking behaviour. This study shows that parents are mainly concerned with preventing life-threatening diseases, such as meningitis, and that parental worry is closely related to a more general societal tendency to want to rule out risk. Parents have adopted diagnostic procedures from professionals that they use at home for reassurance or to indicate early warning signs.

- Which views on illness in children, health care, and parenting influence their decision making?

This paper proposes that parents' help-seeking behaviour after hours can be interpreted as typical for the 'risk society'. ${ }^{11,12}$ However irrational some parents may seem to GPs, their behaviour might be in line with the societal trend towards risk aversion. ${ }^{13}$

\section{METHOD}

The study investigated the decision-making processes of parents by analysing their phone calls to an out-of-hours primary care cooperative and by interviewing them regarding reasons for consultation after immediate care for their child had taken place. As it was assumed that parents' decision-making behaviour is only partly understood, a qualitative investigation was conducted. The main goal was to cover the different viewpoints that structure parents' decisions. The setting of the study was a general practice out-of-hours cooperative that caters for approximately 300000 people in the middle of the Netherlands. Like other Dutch GP cooperatives, it provides care for urgent health problems that cannot wait until regular GP care is available.

Fifty-three parents who visited the cooperative with a sick child between June and November 2006 were randomly selected from all parents who arrived at the out-of-hours cooperative at various specified times during that period. Informed consent was obtained, giving permission to examine the medical record of their child's visit and their phone call to the cooperative. Information about the children's characteristics, diagnosis, treatment, and urgency classification was collected from the medical record. Most parents $(n=47)$ had phoned beforehand and 44 of their telephone calls were traced in the digital records of the telephone system. The phone calls were written out verbatim and analysed.

A total of 19 parents were interviewed at home in the weeks following their visit to the general practice cooperative; these parents were selected purposefully. Earlier research has shown a relationship between consultation rates and socioeconomic status, ${ }^{14}$ or child-related factors such as age and fever. ${ }^{3,7}$ Therefore, to ensure a broad range of opinions, parents from different socioeconomic backgrounds were chosen, as well as children with different medical problems and from different age groups.

The interviews were semi-structured and lasted between 20 and 60 minutes. They were recorded and transcribed. The telephone calls were used to gain insight into how parents voiced the urgency of their children's symptoms shortly after they had decided that out-of-hours care was necessary. The interviews were used to examine the decision-making process in depth, including contributing views and circumstances. The phone calls also served to validate the individual interviews.

In a second phase of the study, eight parents from the same area were interviewed; their children had required immediate referral to hospital care for their medical problems in the preceding 6 months. The decision to interview them was made because most of the parents in the first group had sought consultation for minor afflictions and the researchers wanted to know if the decision-making process differed when children were seriously ill.

Coding was done by hand. An inductive coding technique was used to identify relevant themes in the transcriptions. Codes were also developed within a scheme that categorised the parents' information from micro to macro levels, ranging from their definition of the child's situation to strategies they used to deal with their child's disease and their views on health care in general. ${ }^{15}$ The interviews were conducted by one GP researcher. Two researchers worked on the interpretation of the material in a cyclical process of analysing and reviewing the results.

\section{RESULTS}

Characteristics of the children whose parents participated in the study are detailed in Table 1. Most children were labelled with urgency code U3 by the triaging assistant; this code stands for: 'urgent, assess within several hours for medical or emotional reasons ${ }^{\prime} \cdot{ }^{16}$ However, after examination, a quarter of the children did not need any treatment, and another quarter was only given advice about self-treatment.

The stages in the decision-making process before approaching medical services were the same for parents in both interview groups, whether their children were sick because of a self-limiting disease or a life-threatening condition. This process started when parents noticed abnormal behaviour or abnormal physical symptoms in their child. They tried to think of an explanation for their findings. Was the child ill? Did they have to do something about it? 
They applied their usual repertoire of care, observed and examined their child, and gave medicine if necessary. When parents felt they were losing control of the situation, they reached a turning point and started to think of getting professional help. The reasons they gave for contacting after-hours services or wanting medical advice immediately are summarised in Table 2.

\section{Knowledge of parents and their actions at home}

Most parents said that they had no difficulties in ascertaining that their child was sick. To do so they used the extensive knowledge that they had of the normal behaviour and the normal appearance of their child. Deviation from the norm was usually the first sign that something was wrong. Parents described how their children changed from their normal active selves, became listless, or wanted to sit on their mother's lap:

'She is always a busy little bee. So when she got that very high fever, she would just lay there in that playpen. That is not really like her.'

(Parent 11, interview group 1, complaint abnormal breathing and pallor, no disease found)

Parents watched the appearance of their children: the colour of their faces, the set of their eyes, and even their hair:

'Their behaviour is always very predictable. So it's easier to notice that something is wrong. With $[x]$ for example, he has very cute blond curls. But when he doesn't feel well, when he becomes sickish, his hair turns dull and straight.' (Parent 10, interview group 1, complaint painful shoulder, diagnosis clavicle fracture)

Many parents performed diagnostic procedures on their children before contacting immediate-care services. As well as taking their temperature - the procedure mentioned most frequently - parents had checked for neck stiffness, examined the throat, palpated the abdomen, tested the eyes of their children, searched for bruising, and palpated the fontanelles. Most of these tests seemed to be a copy of diagnostic procedures of doctors. However, the interpretation of the outcome of these tests could differ from the medical viewpoint. Several parents appeared to use the neck-stiffness test to reassure themselves, apparently not knowing that a negative test does not rule out meningococcal disease.

The subject of fever came up in 21 telephone calls and 16 interviews. Parents were aware of fever as a medical symptom, but they diagnosed and
Table 1. Children's characteristics.

Children included at Interview group $1^{\mathrm{b}}$ Interview group $2^{\mathrm{C}}$ cooperative $^{\mathrm{a}}(n=53) \quad(n=19) \quad(n=8)$

\begin{tabular}{lccc}
\hline Age of child, years & & & \\
$0-4$ & 32 & 12 & 6 \\
$5-11$ & 19 & 6 & 1 \\
$12-16$ & 2 & 1 & 1 \\
\hline
\end{tabular}

Urgency classification ${ }^{16}$ assigned

by triaging assistant

U1 (life threatening)

U2 (acute, assess within 1 hour)

U3 (urgent, assess within a $\quad 44$

few hours for emotional

or medical reasons)

U4 (routine, no pressure of time)

Diagnosis (ICPC code chapters)

Skin

Musculoskeletal

Digestive

Respiratory

General and unspecified

Eye

Ear

Psychological

Neurological

Male genital system

Blood and blood-forming organs

0

2

$44 \quad 16$

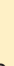

6

$4 \quad 1$

Treatment by GPs

Explanation

Explanation and advice

Prescription

Other treatment

Referral

Unknown

$-$

aData derived from medical records of children's visit to cooperative. ${ }^{b}$ Parents interviewed after visit to cooperative. 'Parents of children referred to hospital. 'BBronchiolitis. ${ }^{\circ}$ Viral disease. ${ }^{\mathrm{N}}$ Meningitis $(\mathrm{n}=2)$; concussion. ${ }^{\mathrm{A}}$ Aplastic anaemia. ${ }^{\circ}$ Viral disease; clavicular fracture. ICPC = International Classification of Primary Care.

interpreted it in their own way. Many considered fever, even low-grade fever or a rising temperature, as an early warning sign. Parents sometimes consciously deviated from doctors' advice, as the following example shows:

Interviewer: 'Do you use certain values to decide when to worry?'

Parent: 'When it's getting near 40, not before then. While I know that my doctor said: "If he has 38.5 and he is drowsy, that is much more serious than when he has 40 and he is still playing".'

Interviewer: 'How did you get the notion that 40 is the limit?'

Parent: 'Don't know, maybe because you have always heard that a child with a fever of $40^{\circ}$ is always a sick child. And in your thoughts 41 is really crucial. So when it rises above 39.5 , I start getting something like: "I don't like this any more".' (Parent 23, interview group 1, complaint high fever and lethargy, diagnosis tonsillitis) 


\begin{tabular}{|c|c|c|c|}
\hline $\begin{array}{r}\text { Durin } \\
\text { call }\end{array}$ & $\begin{array}{l}\text { ing telephone } \\
\text { alla }(n=44)\end{array}$ & $\begin{array}{c}\text { Interview } \\
\text { group } 1^{\mathrm{b}}(n=19)\end{array}$ & $\begin{array}{c}\text { Interview } \\
\text { group } 2^{\circ}(n=8)\end{array}$ \\
\hline \multicolumn{4}{|l|}{ Child-related reasons } \\
\hline Crying, in pain & 14 & 4 & - \\
\hline Fever with or without other symptoms & 9 & 4 & 2 \\
\hline Specific symptoms & 21 & 8 & 6 \\
\hline Abnormal behaviour & 1 & 4 & 4 \\
\hline \multicolumn{4}{|l|}{ Parents' cognitions } \\
\hline Worried, unwilling to take a risk & 7 & 8 & 5 \\
\hline $\begin{array}{l}\text { Wants a diagnosis or wants to } \\
\text { rule out a specific disease }\end{array}$ & 8 & 10 & 2 \\
\hline Wants treatment & 2 & 3 & - \\
\hline In doubt, unsure what to do & 10 & 4 & 3 \\
\hline \multicolumn{4}{|l|}{ Contextual reasons } \\
\hline Former experience of illness in child & 3 & 3 & - \\
\hline $\begin{array}{l}\text { Doesn't want to wait until the next } \\
\text { morning or after the weekend }\end{array}$ & 1 & 6 & 1 \\
\hline Earlier advice was not effective & - & 2 & 2 \\
\hline Has to go to work the next morning & - & 1 & - \\
\hline
\end{tabular}

aphone calls before visit to cooperative. ${ }^{\mathrm{b}}$ Parents interviewed after visit to cooperative. 'Parents of children referred to hospital. right side. I thought l'd give it a firm poke to check if it's real. When I poke in the right lower side, really push on it, she winces.'

(Parent 2, phone group, complaint abdominal pain, diagnosis abdominal pain)

Other parents decided to consult a doctor when their own approach failed or they couldn't find an explanation for their child's symptoms and started to think of a serious condition. Some parents said that their intuition had been important in this process:

'He was 16 days old. At night he already drank a bit less, but I didn't find it alarming. And I noticed that he was irritable when I held him upright, that he didn't like that. In the morning the situation was more or less the same, he didn't drink much. I went shopping on Friday morning and took my eldest to and from school. And when we came back from school, it was around 11.45 and my mother was sitting with him on the sofa and then he was moaning. Then I thought: "A moaning baby, that is unusual". But I wasn't really shocked, I wanted to wait and see. And why I called eventually? I thought: "It is almost weekend, l'd better call". I think it was instinctive, like: "I don't know; it doesn't feel right".'

(Parent F, interview group 2, complaint moaning, diagnosis meningitis)

Parents could become progressively worried until contact with a doctor seemed to be the only recourse for relief: thought: "One plus one makes two. I have to rule something out". I found it necessary to have a definite answer that same evening.'

Interviewer: 'And what did you have to rule out?'

Parent: 'Menin, uh, how do you call it?'

(Parent 41, interview group 1, complaint headache and poor sight, diagnosis low vision right eye)

Parents decided to ask for help when they worried about being incapable of handling the situation themselves. This turning point could come about through worsening of the child's symptoms, the child's discomfort, or because symptoms that were alarming developed:

'Yesterday she wasn't feeling well. But I thought that was normal. She had a stomach ache. Possible. Mommy had her birthday. Didn't pay much attention to it, because it was hot and things like that. But now she is in so much pain that she says she can't walk, because her tummy hurts that much. And it's very painful in the lower

\begin{abstract}
'My own uneasiness mounts during the day. In the morning you make a fresh start: new day, new chances. In the evening you start to fret more. Then I call my mother and I call someone else to ask their opinion. And then finally you reach the point where you will have to take it through the night if you don't act. And what can I do then to reassure myself?'

(Parent 37, interview group 1, complaint fever and poor drinking, diagnosis upper respiratory infection)
\end{abstract}

\section{Not wanting to take a risk}

Many parents talked about their doubts and their concerns. A phrase they often used was: 'I didn't trust the situation'. They monitored themselves and regarded their own feelings as a reason to seek medical advice:

'My husband had gone swimming and she was crying a little. At first I thought: "She just doesn't want to sleep, so let her be". But after a while I 
discovered that it wasn't ordinary crying. So I picked her up and it took quite some time before she had calmed down, while this usually isn't the case. So I really had the feeling that there was something wrong. And my husband returned home and he thought that she was a bit pale and bluish and he found her breathing abnormal. So he was uneasy. And we had always said to each other: if one of us doesn't trust something, we'll go to the doctor.'

(Parent 11, interview group 1, complaint abnormal breathing and pallor, no disease found)

Some parents were particularly worried about the possibility of a life-threatening disease like meningitis or appendicitis. They wanted to avoid being too late and damaging their child. Parents didn't want to 'take a risk' with their child and said that they would rather attend the doctor 'too often, than not often enough'. They expected doctors to take them seriously and reassure them. Interestingly, adequate medical treatment was not mentioned as an expectation:

'They always help me immediately and take me very seriously. That is why I said: "I am always well received". My son is always examined thoroughly. Last time as well. They said immediately that they were going to order an $X$-ray, because they couldn't be completely sure if it wasn't pneumonia. So that is fine. They are very watchful with children.'

(Parent 42, interview group 1, complaint gasping and groaning, diagnosis upper respiratory infection)

Parents wanted to know exactly what was wrong with their child and wanted to exclude serious disease. They felt that risk avoidance was part of their parental role. They emphasised how important their offspring were to them, with expressions like: 'That child is the most important thing you have' or 'That child touches you to the depth of your soul'. They thought it was natural to be upset when their child was ill. Parents of sick children demanded a lot of themselves. They felt they had to keep a close watch on the child and gather relevant information about the situation. They felt responsible for getting medical help on time; they wanted to be assertive in their contacts with medical professionals, and to stand up for their children.

\section{DISCUSSION}

\section{Summary of main findings}

The major finding of this study is that parents take their children to the after-hours service because their interpretation of their children's symptoms gives them reason to worry. When their anxiety has reached a certain level, consulting a doctor seems their only option. They regard the symptoms as signals that their child could become seriously ill. Relief of complaints, one of the traditional reasons for seeing the doctor, does not seem to play an important role in the motivation of these parents: they want to rule out risks. Parents relate their fears to life-threatening conditions that can develop in a short time span, such as meningitis and appendicitis.

Overall, parents ask for immediate care when they are afraid of a serious disease. They seek prevention, diagnosis, and reassurance. Treatment and cure are secondary to them when using out-of-hours services. Parents principally try to regulate their own risk perception. In this sense, the concept of a 'risk culture' could be applied here.

\section{Strengths and limitations of the study}

A strong point of the study is the use of recordings of phone calls that were made immediately after parents had decided to consult, but before they were aware of the outcome of their consultation. However, these phone calls were brief and they were made to obtain professional advice, which could influence the information parents chose to give at that time.

By interviewing parents who had recently needed urgent medical attention for their children, the researchers avoided talking about hypothetical situations; however, as these interviews took place after the event and after the recovery of the children, this could also have influenced the results. Comparison between phone calls and interviews of individual parents showed large similarities with regard to the descriptions of the symptoms and the reasons for contacting the cooperative.

By starting out with a random sample of parents visiting the out-of-hours cooperative for their children, and interviewing parents with varied background characteristics, a broad range of opinions was gathered concerning the research subject. However, the findings are limited to one region of the Netherlands and one out-of-hours cooperative. The second sample with eight parents of children with more serious diseases is a convenience sample. Data from this group have only been used as an addition to findings from the first group and no separate conclusions were drawn from these data.

As the parents knew their interviewer to be a GP, it is possible that they limited their information to things that they thought would be interesting for a GP. For this reason, they may also have left out criticism of doctors or opinions that differed from those of people in the medical position. Even so, various critical comments were recorded concerning 
individual doctors, the organisation of the out-ofhours cooperative, and medical opinions.

\section{Comparison with existing literature}

Parents' preoccupation with risks is, in part, a reflection of former experiences with medical professionals; for example, previous research indicates a positive relationship between the extent of worry about fever and earlier contacts with professionals. ${ }^{17}$ The present study demonstrated that parents copied professional practices at home to rule out serious disease.

The decision-making process parents went through before they decided they needed medical help was similar to the process in non-urgent situations. ${ }^{6,18}$ They monitored their children until circumstances arose that made them feel in need of immediate professional advice. That was the moment when they defined the symptoms of their child as 'urgent'. Earlier studies have shown that worry plays an important part in the decision of parents to consult.,3 However, this worry has so far not been related to the preoccupation with risk that pervades health care, and the central role of risk regulation in society as a whole.

Within so-called 'risk societies', ${ }^{11-12}$ individuals become increasingly aware of health threats. Their trust of authorities is decreasing and, at the same time, they have a greater need for expert knowledge to foresee health threats. ${ }^{12}$ Professional practice and professional language are translated to everyday life. Self-help by patients becomes more important, and there is a shift from cure to prevention. ${ }^{11,12,19,20}$ These general traits of 'risk society' are also characteristic of the way parents dealt with their children's health in the current study.

In modern societies people see themselves as agents of their own future and of their own health. People monitor their health reflexively. This means that they try to anticipate all possible dangers to their own bodies and those of their children, who are also, literally, the embodiment of the future. This task can cause anxiety in parents, who feel that their child's health is dependent on their individual decision making. This anxiety was apparent in the present study and in earlier research by Kai, who also found that a perceived threat to the child and feeling powerless were the main contributors to parental worry. ${ }^{4}$

Visiting the doctor seemed the only way for parents to reduce their uncertainty and anxiety. Parents monitor themselves and their children; their own worry is interpreted as a legitimate reason to see a professional. They have learned to behave that way in a society that is keen on early diagnosis and risk control.

\section{Implications for future research and clinical practice}

GPs should be aware that parents use professional diagnostic procedures at home, the results of which they might interpret differently from doctors. The use of the thermometer is a longstanding example: in the discussion about 'parental fever phobia', which is more than 20 years old, several authors have advocated interventions to educate parents about their misconceptions concerning fever. ${ }^{17,21}$ However, parental anxiety about fever has not diminished. ${ }^{17}$ Using the test for neck stiffness at home to decide if a child is seriously ill is another dubious example of a professional diagnostic procedure that parents use while unfamiliar with its exact medical significance. This practice is not something that doctors should want to encourage, mainly because a negative test, by itself, is not reassuring. As such, further investigation into the use of professional diagnostic procedures at home seems worthwhile.

Putting more effort into the education of parents about acute illnesses in children will not automatically lessen parental fear when parents observe certain symptoms in their children. Part of this fear has been induced by doctors themselves, who also try to stay on the safe side. ${ }^{9}$ How to avoid missing serious infection in children in general practice is an ongoing subject of research and debate, ${ }^{22,23}$ but guidelines that advocate the use of more biomedical measures by GPs, such as heart rate or capillary refill time, can affect the way parents manage their sick children, as these measures might also become generally accepted for use at home. Doctors should realise the long-term effects of their actions on the attitudes of parents. This study shows that whenever a child's symptoms can possibly fit the diagnosis of a life-threatening disease, parents will want to rule out that risk. Knowledge from educational pamphlets or former advice from their doctors do not seem to be sufficient once parents are uneasy about their child's symptoms. Education is useful for several reasons, such as empowering parents, but doctors should be aware that more parental knowledge will probably not reduce the number of non-urgent after-hours consultations for children. Therefore, it seems advisable to steer the discussion away from inappropriate use of out-ofhours facilities, and to accept that parents of sick children will continue to seek advice from doctors at all hours of the day to perform their parental duty of ruling out every possible risk.

\section{Funding body}

The study was undertaken as part of a masters programme in Medical Anthropology and Sociology at the University of Amsterdam 
Ethical approval

Not applicable

\section{Competing interests}

The authors have stated that there are none

\section{Acknowledgements}

We would like to thank the parents who participated in this study, the board and medical receptionists of the out-of-hours cooperative Primair-Blaricum, and the GP group Bijmaten.

\section{Discuss this article}

Contribute and read comments about this article on the Discussion Forum: http://www.rcgp.org.uk/bjgp-discuss

\section{REFERENCES}

1. Giesen PHJ, Mokkink HGA, Ophey G, et al. Hoe urgent is de gepresenteerde morbiditeit op de Centrale Huisartsenpost? [How urgent is the morbidity presented at the GP cooperative?] Huisarts Wet 2005; 48: 207-210.

2. Salisbury C, Trivella M, Bruster S. Demand for and supply of out of hours care from general practitioners in England and Scotland: observational study based on routinely collected data. BMJ 2000; 320(7235): 618-621.

3. Bruijnzeels MA. Illness in children and parental response. [Dissertation] Rotterdam: Erasmus University, 1997.

4. Kai J. What worries parents when their preschool children are acutely ill, and why: a qualitative study. BMJ 1996; 313(7063): 983-986.

5. Kallestrup P, Bro F. Parents' beliefs and expectations when presenting with a febrile child at an out-of-hours general practice clinic. Br J Gen Pract 2003; 53(486): 43-44.

6. Cunningham-Burley S. Mothers' beliefs about and perceptions of their children's illnesses. In: Cunningham-Burley S, McKeganey NP (eds). Readings in medical sociology. London: Tavistock, 1990: 85-109.

7. Saunders NR, Tennis O, Jacobson S, et al. Parents' responses to symptom of respiratory tract infection in their children. CMAJ 2003; 168(1): 25-30

8. Hopton J, Hogg R, McKee I. Patients' accounts of calling the doctor out of hours: qualitative study in one general practice. BMJ 1996;
313(7063): 991-994.

9. Roberts H. Professionals' and parents' perceptions of A\&E use in a children's hospital. Sociological Review 1992; 40: 109-131.

10. Monteny M, Berger MY, van der Wouden JC, et al. Triage of febrile children at a GP cooperative: determinants of a consultation. Br J Gen Pract 2008; 58(549): 242-247.

11. Beck U. Risk society; towards a new modernity. London: Sage Publications, 1992

12. Giddens A. Modernity and self-identity: self and society in the late modern age. Stanford: Stanford University Press, 1991.

13. Burgess A. Cellular phones, public fears, and a culture of precaution. New York: Cambridge University Press, 2004.

14. Neill SJ. Acute childhood illness at home: the parents' perspective. I Adv Nurs 2000; 31(4): 821-832

15. Miles MB, Huberman M. Qualitative data analysis: an expanded sourcebook. Thousand Oaks: Sage Publications, 1994.

16. Dutch College of General Practitioners. NHG-telefoonwijzer voor triage en advies. [Dutch College of GPs' Telephone guideline for triage and advice.] Utrecht: NHG, 2005.

17. Crocetti M, Moghbeli N, Serwint J. Fever phobia revisited: have parental misconceptions about fever changed in 20 years? Pediatrics 2001; 107(6): $1241-1246$.

18. Locker D. Symptoms and illness: the cognitive organization of disorder. London: Tavistock Publications, 1981.

19. Douglas M. Risk and blame: essays in cultural theory. London: Routledge, 1992

20. Lupton D. Risk. New York: Routledge, 1999

21. Kramer MS, Naimark L, Leduc DG. Parental fever phobia and its correlates. Pediatrics 1985; 75(6): 1110-1113.

22. Thompson M, Mayon-White R, Harnden A, et al. Using vital signs to assess children with acute infections: a survey of current practice. $\mathrm{Br} \mathrm{J} \mathrm{Gen}$ Pract 2008; 58(549): 236-241.

23. Cave JA. Managing the acutely ill child. Br J Gen Pract 2008; 58(549): 228-229. 